06.4:06.5

\title{
Особенности импульсного нагрева излучением субтерагерцевого гиротрона при получении нанопорошков оксидов металлов
}

\author{
() А.В. Водопьянов, Д.А. Мансфрельд, А.И. Цветков, А.А. Орловский \\ Институт прикладной фризики РАН, Нижний Новгород, Россия \\ E-mail: avod@ipfran.ru
}

Поступило в Редакцию 8 апреля 2020г.

В окончательной редакции 29 апреля 2020г.

Принято к публикации 29 апреля 2020 г.

\begin{abstract}
Описаны особенности процесса получения нанопорошков оксидов металлов методом испарения-конденсации при импульсном нагреве материала сфокусированным субтерагерцевым излучением. Экспериментально показано, что оптимальные условия для быстрого испарения вещества достигаются при наибольшей возможной мощности импульса и наибольшей возможной скважности при фиксированной средней мощности. В этих условиях можно реализовать нагрев и испарение вещества в сфокусированном пучке излучения за относительно короткое время, пока прилежащие слои испаряемого вещества не прогрелись, не сплавились и сохраняют относительно низкую теплопроводность. Продемонстрировано линейное увеличение скорости испарения при увеличении скважности импульсов нагрева, увеличение достигало пятикратного значения относительно режима непрерывного нагрева.
\end{abstract}

Ключевые слова: нанопорошки, гиротрон, субтерагерцевое излучение, испарение-конденсация.

DOI: 10.21883/PJTF.2020.15.49746.18331

В настоящее время существует значительное число методов получения нанопорошков элементов и их соединений, основанных на использовании принципа испарение-конденсация. Свойства получаемых порошков могут меняться при изменении управляющих параметров процесса $[1,2]$. Формирование наночастиц в таких процессах происходит при конденсации пересыщенного пара испаренного вещества. В этих процессах используются различные способы подвода энергии к испаряемому веществу, применяются различные рабочие среды - как инертные, так и химически активные. В [3-5] было предложено использовать сфокусированное излучение гиротрона для нагрева и испарения вещества. В этих работах использовался технологический гиротрон с частотой излучения $24 \mathrm{GHz}$ и мощностью излучения до $7 \mathrm{~kW}$. Плотность мощности в пятне фокусировки составляла $13 \mathrm{~kW} / \mathrm{cm}^{2}$. В дальнейшем метод получил развитие. В экспериментах, описанных в работе [6], для нагрева использовался гиротрон с частотой излучения $263 \mathrm{GHz}$ и мощностью до $1 \mathrm{~kW}$, плотность мощности в пятне фокусировки составляла до $20 \mathrm{~kW} / \mathrm{cm}^{2}$. Эти исследования стали возможными лишь недавно, когда благодаря развитию техники гиротронов появились надежно работающие источники мощного излучения в субтерагерцевом диапазоне частот $[7,8]$. Удалось существенно увеличить скорость наработки материала, скорость испарения составляла до $300 \mathrm{~g} / \mathrm{h}$. Методика получения нанопорошков с размером частиц 20-100 nm была продемонстрирована на примере $\mathrm{WO}_{3}, \mathrm{ZnO}, \mathrm{SnO}_{2}$.

Процесс нагрева порошка при таком способе воздействия довольно уникален. Одним из несомненных преимуществ является возможность проводить испарение вещества в пятне в режиме гарнисажного тигля - при его холодных стенках. Энергия излучения поглощается в толще материала, причем глубина, на которой осуществляется выделение энергии (профиль поглощения), зависит от нескольких факторов: частоты излучения, свойств материала, температуры материала, фазового состава, дисперсного состава. Ранее в работе [9] исследовалась температурная зависимость поглощения субтерагерцевого излучения оксидами металлов. Были получены ключевые параметры поглощения оксидами металлов излучения с частотой $263 \mathrm{GHz}$ в зависимости от температуры материала и показано, что эффективность поглощения возрастает с температурой.

Широта применимости данного метода нагрева материалов в процессе испарения-конденсации ограничивается максимальной температурой, до которой можно нагреть материал: разогрев должен обеспечить интенсивное испарение вещества. Температура, до которой можно нагреть вещество, определяется балансом подводимой энергии и потерями тепла. При фиксированной мощности генератора излучения и при фиксированной величине площади фокальной перетяжки плотность подводимой мощности определяется длиной поглощения материала, и ее в некоторых допущениях можно считать фиксированной. В то же время потери тепла определяются прежде всего теплопроводностью окружающего вещества и потерями на излучение. Теплопроводность сама по себе зависит от температуры. Для материалов этого класса чем больше температура, тем выше теплопроводность. Поэтому может оказаться выгодным с точки зрения достижения максимально возможных температур проводить процесс испарения импульсным (нестационарным) образом, при котором окружающие слои остаются при меньшей температуре по сравнению 


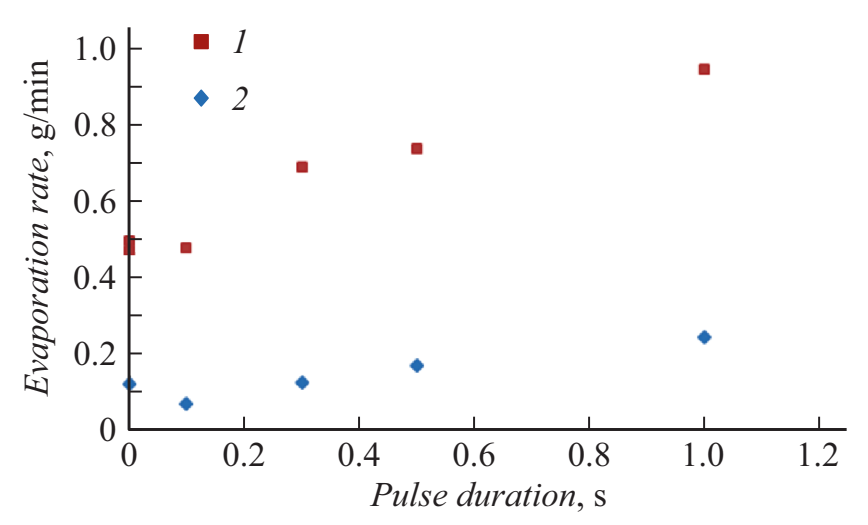

Рис. 1. Зависимость скорости испарения от длительности импульса (0 соответствует непрерывному режиму нагрева). Скважность равна 2. Средняя мощность нагрева составляет 240 (1) и $140 \mathrm{~W}(2)$.

со стационарным значением распределения температуры по нагреваемому образцу. Настоящая работа посвящена исследованию особенностей импульсного нагрева оксидов металлов субтерагерцевым излучением.

Исследования проводились на экспериментальном стенде, который подробно описан в [6]. В качестве источника излучения использовался гиротрон, работающий на основной циклотронной гармонике с частотой излучения $263 \mathrm{GHz}$ и номинальной выходной мощностью $1 \mathrm{~kW}$ как в импульсном, так и в непрерывном режиме [7]. Для достижения плотности мощности микроволнового излучения $20 \mathrm{~kW} / \mathrm{cm}^{2}$ пучок излучения фокусировался в пятно диаметром не более $2.5 \mathrm{~mm}$. Происходило испарение материала за счет микроволнового нагрева поверхности порошка. Поток охлаждающего газа (воздуха) подавался перпендикулярно поверхности образца. Когда воздух смешивался с парами материала, происходили их быстрое охлаждение и конденсация. Полученные частицы осаждались на охлаждаемой водой поверхности. В качестве тестового материала использовался триоксид вольфрама $\left(\mathrm{WO}_{3}\right)$ со средним размером частиц 50-60 $\mu \mathrm{m}$. Температура, при которой начинается существенное испарение триоксида вольфрама, составляет $1200^{\circ} \mathrm{C}[10]$. Скорость испарения вещества определялась по уменьшению массы материала в тигле при помощи электронных весов KERN EG. Параметры получаемого нанопорошка в данной схеме определяются величиной потока закалочного газа, который останавливает рост частиц в пересыщенном паре испаряемого вещества. В качестве закалочного газа в экспериментах использовался воздух, расход воздуха во всех экспериментах был одинаковым и составлял $20 \mathrm{~m}^{3} / \mathrm{h}$. В этих условиях удельная площадь поверхности получаемых частиц в процессе составляет $5 \mathrm{~m}^{2} / \mathrm{g}$, что соответствует среднему размеру частиц около $100 \mathrm{~nm}$ [6]. В описываемых экспериментах получаемые нанопорошки $\mathrm{WO}_{3}$ имели такие же размеры.

На рис. 1 представлены результаты исследования скорости испарения исходного порошка в зависимости от длительности импульса греющего поля. Длительность импульса 0 на графике соответствует режиму непрерывного нагрева в течение $1 \mathrm{~min}$. Во всех экспериментах с импульсным нагревом длительность процесса также составляла $1 \mathrm{~min}$. Это время выбрано таким, чтобы удовлетворить двум условиям: во-первых, стационарное распределение температуры по образцу устанавливается за существенно меньшее время (за несколько секунд); во-вторых, убыль материала за весь процесс незначительна, форма кратера практически не изменяется, кратер углубляется малозаметно. Скважность в данном случае составляла 2. На рисунке приведены зависимости для двух величин средней мощности. Максимальная длительность импульса $1 \mathrm{~s}$ была ограничена техническими возможностями используемого источника питания гиротрона. Показано, что с ростом длительности импульса нагрева и соответственно длительности остывания скорость испарения вещества существенно возрастает, что свидетельствует о большей температуре в центре пятна нагрева. Анализ образованных кратеров также показал наличие существенной разницы в распределении температуры во время проведения процесса: область, занятая расплавленным материалом, больше в том случае, когда длительность греющего импульса меньше.

На рис. 2 представлена зависимость скорости испарения материала от скважности импульсов. Длительность процесса составляла $1 \mathrm{~min}$, длительность импульса нагрева $1 \mathrm{~s}$. Средняя мощность поддерживалась равной $140 \mathrm{~W}$ во всех процессах. Анализ образованных кратеров показывает, что область, занятая расплавленным материалом, больше в том случае, когда скважность импульсов меньше. Из рис. 2 видно, что скорость испарения линейно зависит от скважности. Продемонстрировано пятикратное увеличение скорости испарения при увеличении скважности импульсов нагрева и сохранении средней мощности на одном уровне. Это значит, что энергетические затраты на преобразование порошка в нанофазу обратно пропорциональны скважности. Это позволит существенно оптимизировать процесс по пара-

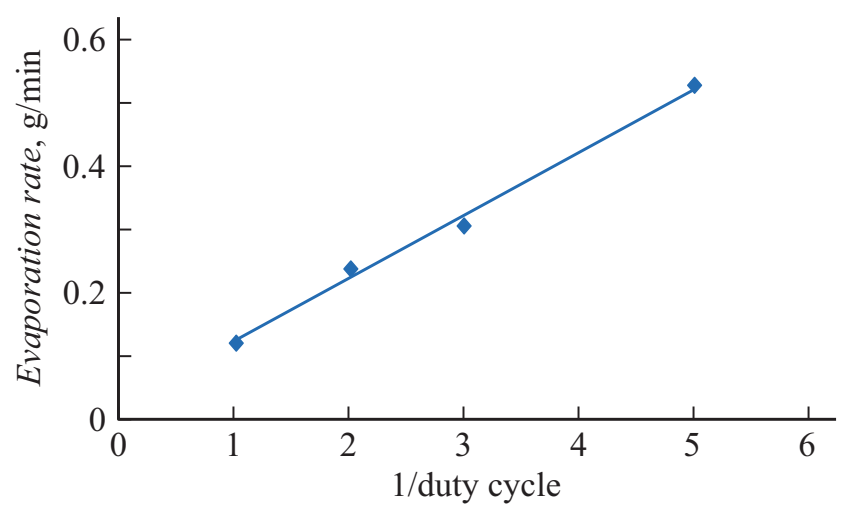

Рис. 2. Зависимость скорости испарения от величины скважности импульсов. Длительность импульса $1 \mathrm{~s}$. Средняя мощность $140 \mathrm{~W}$. Скважность 1 соответствует непрерывному режиму. 
метру вкладываемой энергии в перерабатываемое вещество. В результате проведенных экспериментов можно сделать вывод, что оптимальные условия для быстрого испарения вещества - наибольшая возможная импульсная мощность и наибольшая возможная скважность при фиксированной средней мощности. В этих условиях можно реализовать нагрев и испарение вещества в сфокусированном пучке излучения за относительно короткое время, пока прилежащие слои испаряемого вещества не прогрелись, не сплавились и сохраняют относительно низкую теплопроводность. Таким образом, показано, что при импульсном режиме нагрева удается реализовать условия, в которых потери тепла, связанные с теплопроводностью материала, минимальны и при фиксированной средней мощности возможно достижение бо́льших температур, чем при нагреве непрерывным излучением. При этом параметры получаемого нанопорошка определяются величиной потока закалочного газа и не зависят от режима нагрева.

\section{Финансирование работы}

Работа выполнена при поддержке Российского научного фонда (проект № 18-79-10194).

\section{Конфликт интересов}

Авторы заявляют, что у них нет конфликта интересов.

\section{Список литературы}

[1] Nogi K., Naito M., Yokoyama T. Nanoparticle technology handbook. Elsevier, 2012. $730 \mathrm{p}$.

[2] Altavilla C. Upconverting nanomaterials: perspectives, synthesis, and applications. CRC Press, 2016. 369 p.

[3] Алексеев Н.В., Водопьянов А.В., Изотов И.В., Самохин А.В., Синайский М.А., Цветков Ю.В. // Физика и химия обраб. материалов. 2014. № 1. С. 17-20.

[4] Samokhin A.V., Alexeev N.V., Vodopyanov A.V., Mansfeld D.A., Tsvetkov Y.V. // J. Nanotechnol. Eng. Med. 2015. V. 6. P. 011008.

[5] Самохин А.В., Алексеев Н.В., Водопьянов А.В., Мансфельд Д.А., Синайский М.А., Цветков Ю.В., Еремеев А.Г., Плотников И.В. // Химия высоких энергий. 2015. Т. 49. № 4. C. $302-307$.

[6] Vodopyanov A.V., Samokhin A.V., Alexeev N.V., Sinayskiy M.A., Tsvetkov A.I., Glyavin M.Y., Fokin A.P., Malygin V.I. // Vacuum. 2017. V. 145. P. 340-346.

[7] Glyavin M.Y., Chirkov A.V., Denisov G.G., Fokin A.P., Kholoptsev V.V., Kuftin A.N., Luchinin A.G., Golubyatnikov G.Y., Malygin V.I., Morozkin M.V., Manuilov V.N., Proyavin M.D., Sedov A.S., Sokolov E.V., Tai E.M., Tsvetkov A.I., Zapevalov V.E. // Rev. Sci. Instrum. 2015. V. 86. P. 054705.

[8] Denisov G.G., Glyavin M.Y., Fokin A.P., Kuftin A.N., Tsvetkov A.I., Sedov A.S., Soluyanova E.A., Bakulin M.I., Sokolov E.V., Tai E.M., Morozkin M.V., Proyavin M.D., Zapevalov V.E. // Rev. Sci. Instrum. 2018. V. 89. P. 084702.
[9] Tsvetkov A.I., Vodopyanov A.V., Mansfeld D.A., Fokin A.P. // J. Infrared Millimeter Terahertz Waves. 2019. V. 40. P. 991997.

[10] Wriedt H.A. // Bull. Alloy Phase Diagrams. 1989. V. 10. P. $368-384$ 